\title{
A TÉCNICA DE KATO PARA O DIAGNÓSTICO COPROLÓGICO DE INFECÇÕES PARASITÁRIAS *
}

\author{
Jairo Gonçalves Molina * *
}

Empregando-se 76 espécimens de fezes examinados pelo método de Kato modificiado por Martin e Beaver (4), fêz-se a comparação com a técnica da sedimentação pelo método de Hoffman, Pons e Janer.

Excetuando o diagnóstico das infecçóes polo $\mathrm{T}$. trichurus, nas quais houve evidentes vantagens do método de Kato, não se pode confirmar a superioridade do método de Kato, pelo menos nas condições do laboratório clínico normal.

o autor frisa porém, que por falta de espécimens adequados não foi possivel testar o método nas inferções pelo $\mathrm{S}$. mansoni, campo que se ressente da falta de técnicas adequadas para o diagnóstico de infecções discretas e no qual se antecipam maiores virtudes do método de Kato.

\section{INTRODUÇÃO}

Dois requisitos fundamentais são visados pelos exames coprológicos nas infecçōes parasitárias: elevada sensibilidade do método e utilidade na avaliação quantitativa destas infecções (contagem de ovos).

Devendo o método ainda ser simples e de rápida execução, imprescindivel para os inquéritos em massa, compreende-se que nem sempre são cumpridas ambas as finalidades pelas técnicas correntemente empregadas na prática.

A sensibilidade é de fácil obtenção nas helmintoses mais comuns com elevada ovoposição diária por fêmea, como no caso do $A$. lumbricoides, $N$. americanus, $T$. trichiurus. O emprêgo do método da sedimentação (Hoffman, Pons e Janer, 1), método simples e rápido, pode nêstes casos levar a resultados plenamente satisfatórios.

Diferente é o problema quando se enfrenta a necessidade de diagnosticar corretamente infecções acompanhadas de escassa ovoposição, como no caso da esquistossomose mansônica, seja na presença de número menor de parasitas no organismo, seja nas infecções antigas, em que apreciável proporção dos ovos é retida nos tecidos. Nêstes casos a boa sensibilidade exige exame de maior quantidade de matéria fecal, aumentando-se assim a probabilidade do encontro de ovos de $S$. mansoni. Isto pode ser conseguido através da leitura de maior número de lâminas de sedimento (3), artifício que aumenta significativamente as cifras de prevalência da helmintose em inquéritos epidemiológicos. Não há realmente necessidade de

* Trabalho da Divisão de Medicina Preventiva, Faculdade de Medicina de Mogi das Cruzes, São Paulo. (Serviço do Prof. Dr. Kurt Kloetzel).

* Acadêmico de Medicina.

Recebido para publicação em 17.11.70. 
recorrer a biópsia retal para o diagnóstico da esquistossomose ou o seu contrôle de cura: a repetição do exame cumpre a mesma finalidade. Prata considera 5 exames coprologicos de sensibilidade igual a de uma biópsia retal pela técnica usual (5) .

Diverso é o problema quando se trata da avaliação quantitativa das infecçōes, recurso cada vez mais importante diante da compreensão crescente de que a patologia determinada pelas helmintoses (pelo menos a ancilostomíase e a esquistossomose), pode ser função da carga parasitária.

Nêstes casos, é importante assegurar-se de que é examinada uma amostra significativa do bôlo fecal. Mostra-se inconveniente a passagem de fezes por telas muito estreitas, ou por diversas dobras de gaze (com o que se perde substancial fração dos ovos de helminto), nem pode atribuir-se valor à contagem dos ovos no sedimento obtido pelo método de Hoffman, Pons e Janer, pelo fato adicional dêste sedimento variar de composição nas diferentes camadas.

Conseguir - se sensibilidade e precisão na avaliação da ovoposição exige pois, o examé de maior quantidade de fezes do que a usada nos métodos usuais e que estas fezes preferivelmente não sejam filtradas por tela ou gaze, nem diluída com água.

O grande problema a enfrentar por semelhante método é a dificuldade na leitura das lâminas assim preparadas.

Foi êste o obstáculo que o método de Kato se propōe resolver (2).

Um exame crítico do método de Kato numa série de exames coprológicos constitui objetivo do presente trabalho.

\section{MATERIAL E MÉTODOS}

Não pretendemos descrever o método em tôdas as suas minúcias, uma vez que estas foram adequadamente descritas por outros autores (4).

Em essência a inovação trazida pelo método de Kato é a clarificação do esfregaço de fezes grosso por solução de glicerina, com o que fica reduzida a dificuldade na leitura. Consegue-se êste resultado através do emprêgo de retângulos de celofane $(22 \times 30 \mathrm{~mm})$, deixadas durante
24 horas ou mais, numa solução contendo $100 \mathrm{ml}$. de água, $100 \mathrm{ml}$. de glicerina pura e $1 \mathrm{ml}$. de solução a $3 \%$ de verde de malaquita (o último ingrediente pode ser dispensado)

Com um aplicador especial, ou com uma espátula, transfere-se um pêso padrão de fezes para uma lâmina de vidro. Em seguida cobre-se com o pedaço de celofane, inverte-se a preparaçao, exercendo firme pressão contra uma superfície lisa e resistente. O "esfregaço" é deixado clarear - processo que conforme a temperatura, dura de 30 a 60 minutos. Uma clarificação insuficiente traz cs óbvios inconvenientes do "thick smear', um periodo de clarificação demasiadamente longo acarreta consequências não menos indesejáveis: ovos de ancilostomídeos podem colabar e desaparecer para o observador; ovos de $S$. mansoni tornam-se de reconhecimento mais difícil.

Segundo a modificação introduzida por Martin e Beaver (4), fezes com apreciável quantidade de fibras ou outros detritos são primeiramente passadas por tela metálica de 105 malhas por polegada. Uma ou duas gramas do material sāo colocadas sôbre uma placa lisa, a tela é firmemente comprimida contra o espécimen, e a amostra para exame é colhida na porção que atravessou as malhas da tela.

Em nosso trabalho operamos com espécimens de 50 miligramas de fezes. A pesagem foi evitada, usando-se em seu lugar o exame de um volume-padrão de fezes (correspondendo a 50 miligramas aproximadamente), colhido num receptáculo apropriado, provido de um êmbolo com o qual se transferia o espécimen para a lâmina de vidro.

\section{RESULTADOS}

Examinaram-se 76 espécimens sucessivos entregues para exame coprológico num laboratório clínico de Mogi das Cruzes. Foram examinados por dois observadores independentes, um dos quais utilizava o método de Kato modificado, outro o método de Hoffman, Pons e Janer. o confronto entre as duas técnicas realizou-se sòmente ao término da série de exames.

o quadro seguinte faz a comparação entre os achados: 


\begin{tabular}{|c|c|c|c|}
\hline \multirow{2}{*}{ Achados } & \multicolumn{2}{|c|}{ Prevalência pelo } & \multirow{2}{*}{$\begin{array}{l}\text { Prevalência } \\
\text { combinada }\end{array}$} \\
\hline & Kato & Hoffman & \\
\hline $\begin{array}{lll}\cdots & \cdots & \cdots \\
\cdots & \cdots & \end{array}$ & & 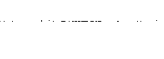 & $\cdots$ \\
\hline Entamoeba coli - cistos ....... & 9 & 12 & 14 \\
\hline Giardia lamblia - cistos $\ldots \ldots \ldots \ldots \ldots$ & 3 & 4 & 4 \\
\hline Trichocephalus trichiurus $\ldots \ldots \ldots \ldots \ldots \ldots$ & 27 & 14 & 31 \\
\hline Ascaris lumbricoides $\ldots \ldots \ldots \ldots \ldots \ldots$ & 19 & 27 & 29 \\
\hline Enterobius vermicularis ....... & 1 & 0 & 1 \\
\hline Ancilostomideos - ovos $\ldots \ldots \ldots \ldots \ldots$ & 6 & 9 & 9 \\
\hline Ancilostomídeos - larvas .. & 0 & 3 & 3 \\
\hline Schistosoma mansoni. ......... & 2 & 2 & 2 \\
\hline Negativos.$\ldots \ldots \ldots \ldots \ldots \ldots \ldots \ldots \ldots \ldots \ldots$ & 23 & 20 & 16 \\
\hline
\end{tabular}

A primeira impressão deixada pela nova técnica não foi favorável. Afora a dificuldade óbvia de conseguir-se uma amostra padrão de matéria fecal no caso de evacuações líquidas ou semi-líquidas, óbice de todos os métodos coprológicos quantitativos, foram anotadas outras dificuldades:

Assim no caso de fezes de coloração escura, a clarificação não é satisfatória, persistindo a dificuldade na leitura de esfregaços espessos.

A presença de muco e catarro, ocorrência assaz freqüente, também traz obstáculos à leitura, pois a matéria fecal não se espalha uniformemente pela lâmina.

A necessidade de focalizar repetidamente em diferentes planos do preparado tem como conseqüência maior demora na leitura, bem como acarreta o risco de passarem desapercebidos alguns ovos presentes, pelo menos no caso do observador muito atarefado, premido pela falta de tempo.

Resta a ver se êstes inconvenientes são compensados por eventuais virtudes do método de Kato.

\section{DISCUSSĀO}

A análise dos resultados desta prova preliminar não revela especiais vantagens para o método de Kato, exceto no que tange a ovos de $T$. trichurus.

A flagrante contradição no caso de $A$. lumbricoides deverá ser atribuída, provà- velmente, à freqüência de fezes escuras nesta série, com conseqüente dificuldade na visualização dêstes ovos.

O método não foi recomendado para infeccões por protozoários, os achados sendo incluídos na tabela sem a pretensão de traduzir a eficiência dos dois métodos coprológicos nêste tipo de parasitismo.

Os nossos achados contrastam-se com o entusiasmo com que o método de Kato é olhado alhures. No Japão êste métođo é usado largamente em inquéritos coprológicos. No trabalho de Martin e Beaver (4), para citar outro exemplo, a técnica é encarada com igual otimismo, pelo que parece.

Segundo êstes autores o método de Kato geralmente resulta em mais elevada contagem de ovos de $S$. mansoni do que pelos métodos de Stoll e de Bell, superando-os igualmente no que tange a reproducibilidade dos resultados. Comparado com o método quantitativo de Stoll, foi maior, igualmente, a sensibilidade do método de Kato no diagnóstico da ascaridíase, tricuríase e esquistossomose. Mas eram menos acentuadas as diferenças quando a comparação era feita com o método de Hoffman, Pons e Janer, embora êste último seja sabidamente, inadequado ao exame quantitativo.

E possível que pesquisadores de laboratório, interessados na avaliação crítica do método de Kato, encontrem maior simpatia pelo método, sabendo superar as dificuldades técnicas encontradas ao primeiro contato com esta nova técnica. Entre- 
tanto, visamos ao empreender o estudo, testar a aceitabilidade dentro da rotina de um laboratório clínico, e nêste sentido o método de Kato mostrou-se deficiente.

Reconhecemos que o problema crítico dos inquéritos coprológicos ainda é a esquistossomose mansônica, na qual säo freqüentes contagens de ovos tão baixas que é reduzida a probabilidade de diagnóstico no exame de fezes corriqueiro.

Antecipamos mesmo que nossos resultados seriam bem mais alvissareiros, se contássemos em Mogi das Cruzes com ponderável proporção de infecções por $S$. mansoni. Nêste campo é provável que o emprêgo da amostra de 50 miligramos se acompanharia de reais vantagens.

Este estudo ficará reservado para o futuro. Não temos, também, presentemente dados para julgarmos a precisão da contagem de ovos nas fezes, ou reproducibilidade destas contagens, parâmetros de suma importância, particularmente no terreno cientifico.

\section{AGRADECIMENTOS}

Nossos agradecimentos aos Drs. Hirofumi Iwai e Jamil K. Nassri, possuidores do laboratório clínico no qual procedemos o presente trabalho.

\section{SUMMARY}

$A$ total of 76 stcol specimens were examined by the Kato method (as modified by Martins and Beaver), and a comparison made with Hoffman's sedimentation method.

With the sole exception of infections by $\mathbf{T}$. trichiurus, in which Kato's method was clearly superior, the author was unable to confirm the alleged virtues of this procedure, at least under the conditions of the clinical laboratory.

The author wishes to stress, however, that it has not been possible to test the method in S. mansoni infections, due to lack of positive specimens. In this field the absence of a technique adequate for the diagnosis of light infections is accutely felt, and it would be possible to antecipate more hopeful results by the use of the Kato procedure.

\section{BIBLIOGRAFIA}

1 - HOFFMAN, W. A., PONS, J. A., e JANER, J. L. - The sedimentationconcentration method in Schistosomiasis mansoni. Pôrto Rico, J. Pub. Healt \& Trop. Med. 9: 283-291, 1934.

2 - KATO, K. \& MIURA, M. - Comparative examinations. Jap. J Parasit., 3: 35,1954

3 - KLOETZEL, K. - Some quantitative aspects of diagnosis and epidemio- logy in Schistosomiasis mansoni. Amer. J. Trop. Med. \& Hig. 12: 334337, 1963.

4 - MARTIN, L. K. \& BEAVER, P. C. Evaluation of Kato thick-smear technique for quantitative diagnosis of helminth infections. Amer. $\mathrm{J}$. Trop. Med. \& Hig., 17: 382-391, 1968.

5 - PRATA, A. - Informação pessoal a K. Kloetzel. 